\title{
Hyperbaric oxygen therapy for the treatment of radiation-induced macular ischemia
}

This article was published in the following Dove Press journal:

Clinical Ophthalmology

7 May 2010

Number of times this article has been viewed

\section{Shamim A Haji ${ }^{1,2}$ \\ Ronald EP Frenkel 1,2,3}

'Eye Research Foundation, Stuart, FL, USA; ${ }^{2}$ East Florida Eye Institute, Stuart, FL, USA; ${ }^{3}$ Bascom Palmer Eye Institute, Miami, FL, USA
Correspondence: Ronald EP Frenkel 509 SE Riverside Dr Suite 302, Stuart, FL 34994, USA

Tel + I 772-287-9000

Fax +I 772-287-0507

Email efleye@aol.com
Purpose: To report a case of radiation-induced macular ischemia where vision and macular perfusion improved after hyperbaric oxygen (HBO) therapy.

Methods: A 62-year-old male patient developed radiation-induced macular ischemia after he was treated with radiation for brain glioma. The patient presented with best spectacle-corrected visual acuity (BSCVA) acuity of 20/400 in his right eye. Optical coherence tomography (OCT) showed central macular thickness of $468 \mu \mathrm{m}$. The patient received focal laser, intravitreal triamcinolone, and HBO therapy.

Results: The patient's vision improved from 20/400 to 20/100 after focal laser and intravitreal triamcinolone. His central macular thickness improved from $468 \mu \mathrm{m}$ to $132 \mu \mathrm{m}$. After receiving HBO therapy, his VA improved to $20 / 50$ and fluorescein angiography showed improvement in macular perfusion.

Conclusion: HBO therapy improves macular perfusion in patients with radiation-induced macular ischemia.

Keywords: macular ischemia, visual acuity, hyperbaric oxygen therapy, macular perfusion

Stallard first described radiation retinopathy in 1933 in patients receiving ocular irradiation with radon seeds for retinoblastoma and retinal capillary hemangioma. ${ }^{1}$ Radiation retinopathy is an occlusive microangiopathy resulting in tissue ischemia secondary to endothelial cell loss and capillary closure occurring after ionizing radiation treatment. Radiation retinopathy has been seen after both radioactive plaque and external beam radiation for ocular and nonocular diseases. Radiotherapy has been a great advance in the treatment of life- and sight-threatening conditions. It is being used in increasing frequency for ocular and nonocular diseases, as a result of which cases of radiation retinopathy may become more prevalent. Usually the vision loss in radiation retinopathy is secondary to macular edema and subsequent ischemia, neovascular glaucoma, and radiation optic neuropathy. Currently, no definitive therapy is available for the treatment of radiation retinopathy. Kinyoun et $\mathrm{al}^{2}$ reported the first successful treatment of radiation-induced macular edema with panretinal photocoagulation, and at present this is the most widely-used treatment for radiation retinopathy. Other treatments like intravitreal triamcinolone and bevacizumab have been shown to be effective in treating radiation-induced macular edema. ${ }^{3,4}$ While the use of hyperbaric oxygen (HBO) therapy for radiation-induced optic neuropathy has been described, to date, its use for radiation-induced macular ischemia has not been described. ${ }^{5}$ Over the last two decades, animal studies, clinical trials, and well-validated clinical experience 

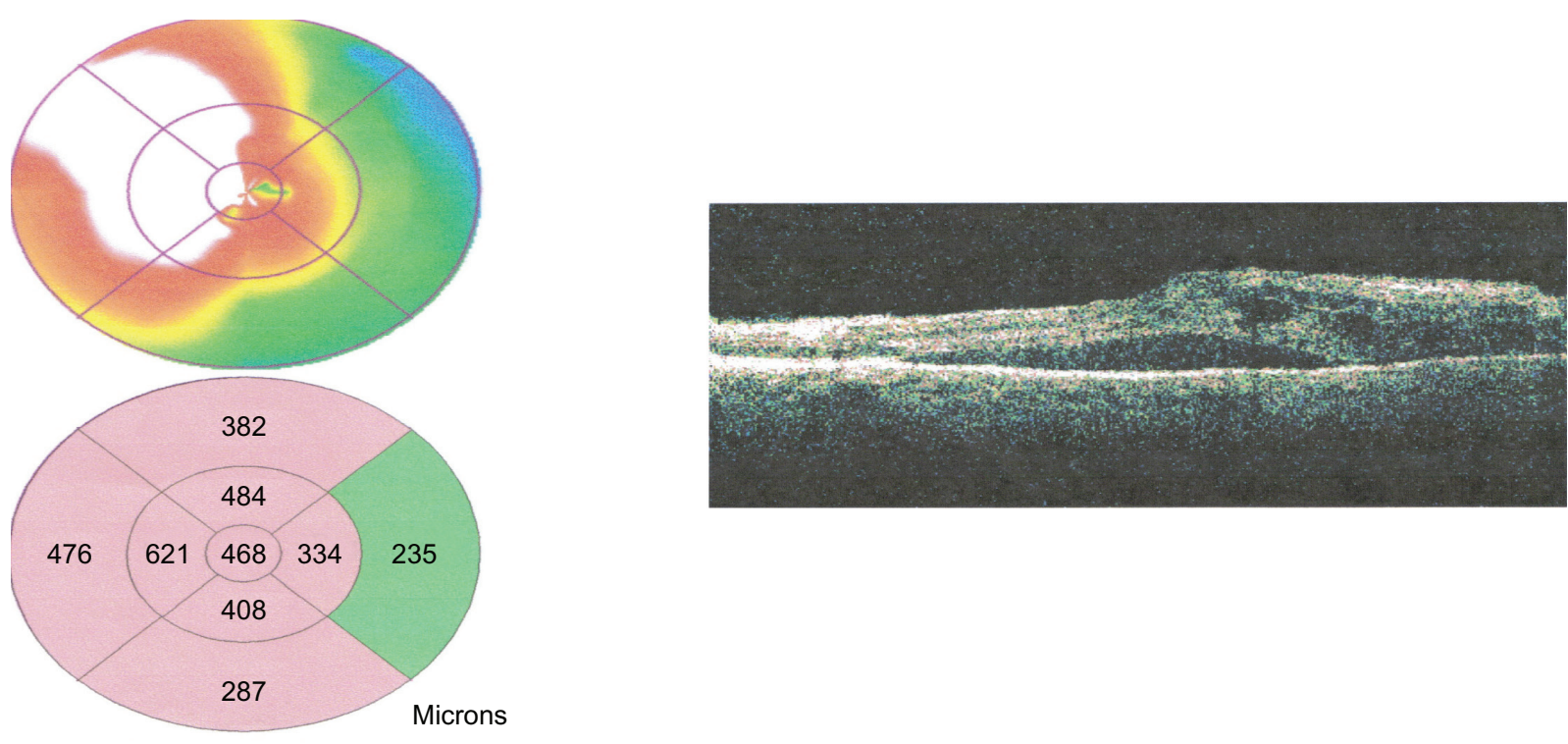

Figure I (Left) Optical coherence tomography retinal color map (top) and thickness map (bottom) showing central macular thickness of 468 um before any treatment. (Right) Horizontal line scan of macula showing intraretinal and subretinal fluid with large serous retinal detachment. At presentation, best spectacle-corrected visual acuity was 20/400.

have suggested the efficacy of HBO for many indications, and recently there has been a renewed interest in this field.

We report a 62-year-old Hispanic male who developed radiation-induced macular edema after he was treated with radiation for a brain glioma. The patient presented with bestcorrected visual acuity BC of 20/400 in his left eye and 20/25 in his right eye. Optical coherence tomography (OCT) of his right eye showed a central macular thickness of $468 \mu \mathrm{m}$ (Figure 1). One week after presentation, the patient received one session of focal laser, and six weeks after initial presentation his visual acuity in his left eye remained unchanged. At that time, he received one injection of intravitreal triamcinolone (4 mg). Three months after initial presentation, his vision improved from 20/400 to 20/100 and his foveal thickness reduced to $132 \mu \mathrm{m}$ with complete resolution of the retinal fluid (Figure 2).

Three months after initial presentation, after receiving one session of focal laser, and one injection of intravitreal triamcinolone (IVT), the patient then received a total of 18 HBO treatments over a one-month period (100\% oxygen
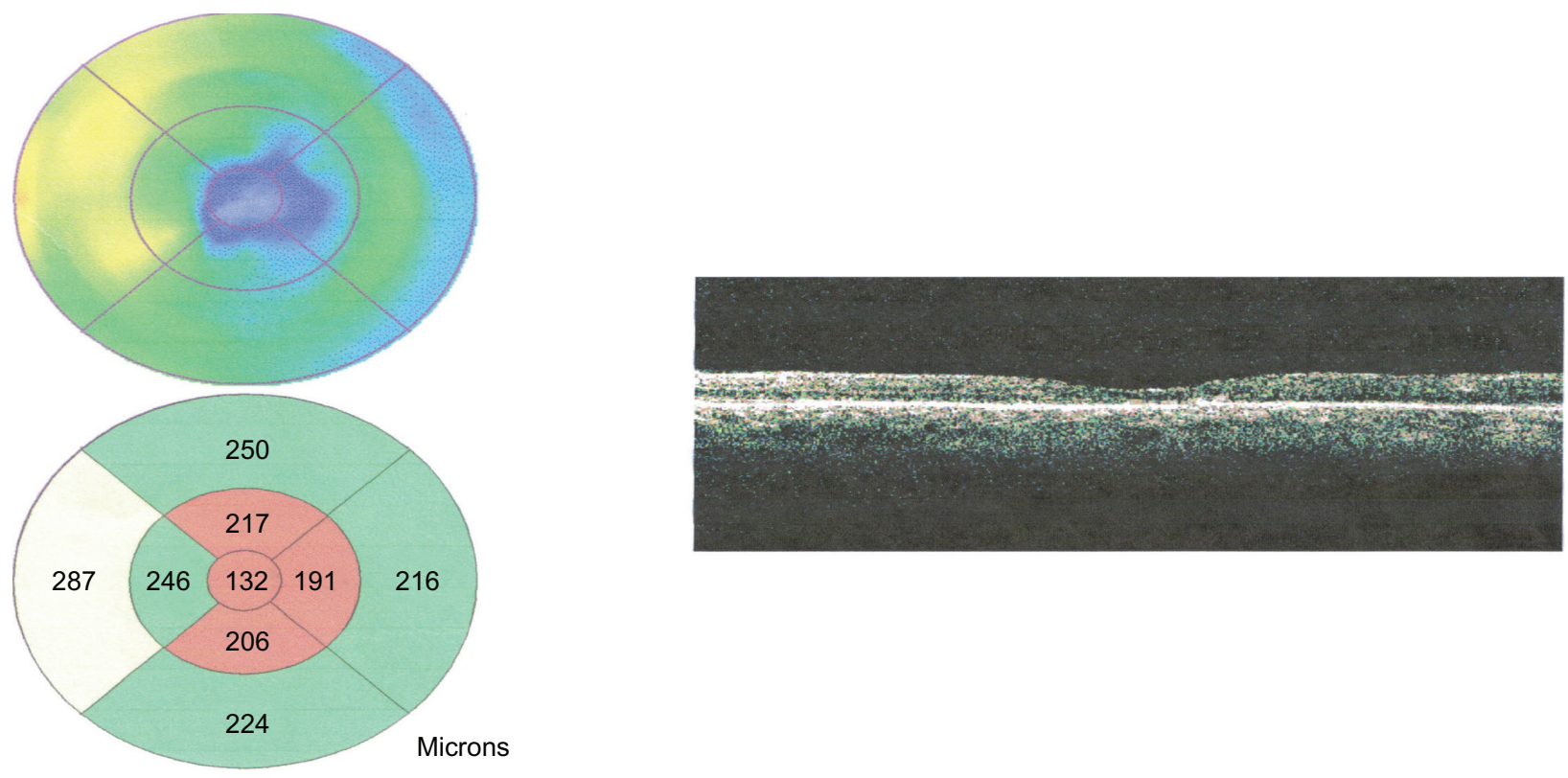

Figure 2 (Left) OCT color retinal map (top) and thickness map (bottom) showing regression of central macular thickness to I32 $\mu$ m. (Right) Horizontal line scan showing no intraretinal fluid or serous retinal detachment after treatment with focal laser and intravitreal injection of triamcinolone. BSCVA improved from $20 / 400$ to $20 / 100$. 

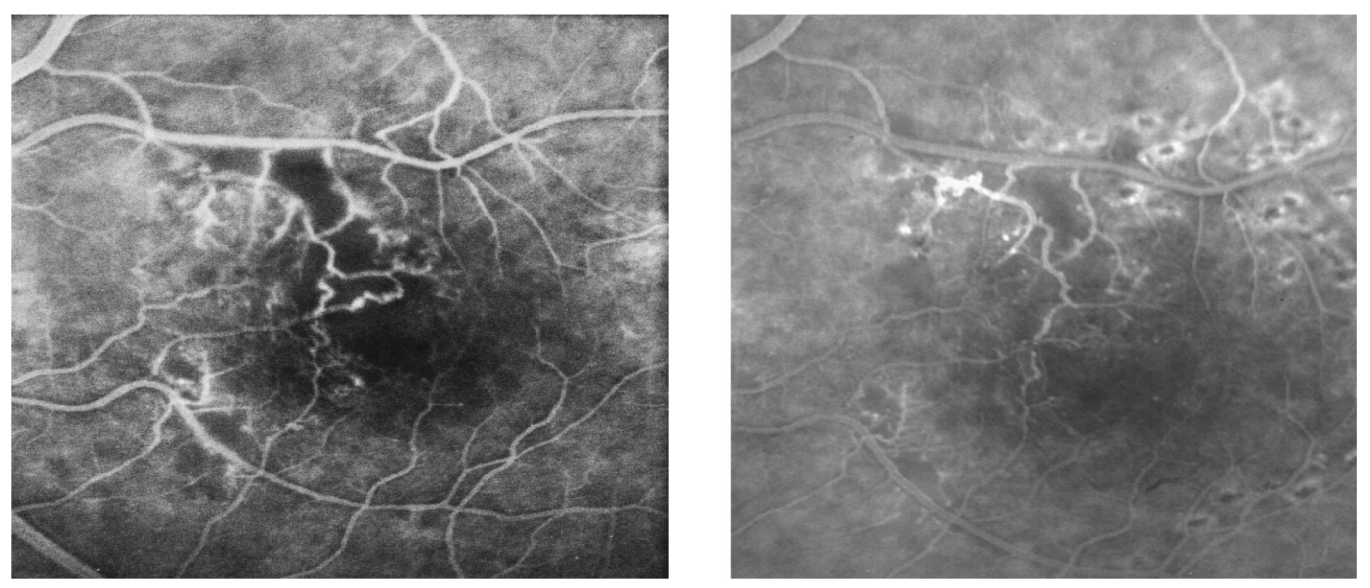

Figure 3 Late phase fluorescein angiography, (Left) showing collaterals and ischemia of the macula before HBO therapy. (Right) showing improvement of collaterals and ischemia after HBO therapy. BSCVA improved from 20/100 to 20/50 after the HBO therapy.

Abbreviations: BSCVA, best spectacle-corrected visual acuity; $\mathrm{HBO}$, hyperbaric oxygen.

at two atmospheres for 90 minutes; two air breaks of 5 minutes each). After undergoing $\mathrm{HBO}$ treatment, his visual acuity continued to improve to 20/50 with stable central macular thickness, though his macular perfusion showed little change as demonstrated by fluorescein angiography (Figure 3).

Though it is unclear in our patient if focal laser had any definite effect, intravitreal triamcinolone resulted in a marked improvement in macular thickness, returning it to normal, and improving vision from 20/400 to 20/100. After the patient received a series of $\mathrm{HBO}$ treatments, the vision improved further from $20 / 100$ to $20 / 50$, while the macular thickness on OCT remained stable. Fluorescein angiography demonstrated some improvement in macular perfusion (Figure 3). Considering that there was no macular edema seen on OCT at the time when patient began HBO therapy, we believe that the patient's improvement in visual acuity from 20/100 to 20/50 was because of improvement in the macular ischemia after he received $\mathrm{HBO}$ therapy. However, it is possible that the triamcinolone may have contributed to the effect seen with the HBO therapy.

Treatments like focal laser, intravitreal triamicinolone and intravitreal bevacizumab may help in reducing the macular edema, as happened in our patient, but they really do not directly address the ischemic component of the condition that permanently contributes to vision loss. There is a growing interest in the use of HBO therapy in medicine in general, and in ophthalmology in particular. The conditions for which HBO therapy has shown clear scientific evidence are decompression sickness, arterial gas embolism, and severe carbon monoxide poisoning. ${ }^{6}$ It has also been shown to be useful as an adjunctive therapy in prevention and treatment of radiation-induced bone injury (osteoradionecrosis), skin grafts and flap healing, and chlostridial myonecrosis. There is some suggestive scientific evidence of beneficial effects of HBO therapy in other conditions like refractive osteomyelitis, acute traumatic ischemic injury, radiation-induced cystitis, and prolonged failure of wound healing such as in diabetic foot ulcers.

HBO therapy has also been shown to be beneficial in occlusive vasculopathies such as central retinal artery occlusion, branch retinal artery occlusion, and cystoid macular edema secondary to retinal vein occlusions. ${ }^{5}$ During HBO therapy, $100 \%$ oxygen is applied at a very high pressure twoto three-fold of that found in the air at sea level. The higher concentration and pressure of oxygen increases the amount of oxygen dissolved in the plasma, and also increases the tissue gradient to transfer oxygen into the tissue. The resultant hyperoxia increases the tissue's consumption of oxygen, and initiates cellular and vascular repair mechanisms. ${ }^{7-9}$ HBO therapy affects many of the components involved in ischemia-reperfusion injury, including polymorphonuclear leukocyte function, endothelial cellular adhesion molecule expression, nitric oxide production, nitric oxide synthase expression, cellular energetic, lipid peroxidation, and microvascular blood flow. ${ }^{5}$

Considering that the pathophysiology of radiation-induced macular ischemia is similar to other occlusive vasculopathies in which HBO therapy has been shown to be beneficial, we believe that HBO therapy in radiation-induced macular ischemia may be helpful. Further evaluation of HBO treatment in patients with radiation-induced macular ischemia is warranted.

\section{Disclosure}

The authors report no conflicts of interest in this work. 


\section{References}

1. Stallard HB. Radiation energy as (a) a pathogenic (b) a therapeutic agent in ophthalmic disorders. Br J Ophthalmol. 1933;1:70.

2. Kinyoun JL, Chittum, ME, Wells CG. Photocoagulation treatment of radiation retinopathy. Am J Ophthalmol. 1988;105:470-478.

3. Sutter FK, Gillies MC. Intravitreal triamcinolone for radiation-induced macular edema. Arch Ophthalmol. 2003;121(10):1491-1493.

4. Gupta A, Muecke JS. Treatment of radiation maculopathy with intravitreal injection of bevacizumab (Avastin). Retina. 2008;28(7):964-968.

5. Oguz H, Sobaci G. The use of hyperbaric oxygen therapy in ophthalmology. Surv Ophthalmol. 2008;53(2):112-120.
6. Leach RM, Rees PJ, Wilmshurst P: ABC of oxygen: Hyperbaric oxygen therapy. BMJ. 1998;317:1140-1143.

7. Sahni T, Hukku S, Jain M, Prasad A, Prasad R, Singh K. Recent advances in hyperbaric oxygen therapy. The Association of Physicians of India Medicine Update. 2004;14:1-8.

8. Leber KA, Eder HG, Kovac H, Anegg U, Pendl G. Treatment of cerebral radionecrosis by hyperbaric oxygen therapy. Stereotact Funct Neurosurg. 1998;70 Suppl 1:229-236.

9. Wanebo JE, Kidd GA, King MC, Chung T. Hyperbaric oxygen therapy for treatment of adverse radiation effects after stereotactic radiosurgery of arteriovenous malformations: case report and review of literature. Surg Neurol. 2009;72(2):162-167.
Clinical Ophthalmology

\section{Publish your work in this journal}

Clinical Ophthalmology is an international, peer-reviewed journal covering all subspecialties within ophthalmology. Key topics include: Optometry; Visual science; Pharmacology and drug therapy in eye diseases; Basic Sciences; Primary and Secondary eye care; Patient Safety and Quality of Care Improvements. This journal is indexed on

\footnotetext{
Submit your manuscript here: http://www.dovepress.com/clinical-ophthalmology-journal
}

\section{Dovepress}

PubMed Central and CAS, and is the official journal of The Society of Clinical Ophthalmology (SCO). The manuscript management system is completely online and includes a very quick and fair peer-review system, which is all easy to use. Visit http://www.dovepress.com/ testimonials.php to read real quotes from published authors. 